Ferrata Storti Foundation

\title{
Characteristics and outcomes of patients with essential thrombocythemia or polycythemia vera diagnosed before 20 years of age: a systematic review
}

Jean-Christophe lanotto, ${ }^{1,2}$ Natalia Curto-Garcia, ${ }^{1}$ Marie Lauermanova,,${ }^{1,3}$ Deepti Radia, ${ }^{1}$ Jean-Jacques Kiladjian ${ }^{4}$ and Claire N. Harrison ${ }^{1}$

${ }^{1}$ Department of Haematology, Guy's and St Thomas' NHS Trust, London, UK; '2Service d'Hématologie Clinique, Institut de Cancéro-Hématologie, Centre Hospitalier Régional et Universitaire de Brest, Brest, France; ${ }^{3}$ nstitute of Hematology and Blood Transfusion, Prague, Czech Republic and ${ }^{4}$ Centre d'Investigation Clinique, Hôpital St Louis, Paris, France
Haematologica 2019

Volume 104(8):1580-1588

\section{Correspondence: \\ CLAIRE N HARRISON \\ claire.harrison@gstt.nhs.uk \\ Received: June 29, 2018. \\ Accepted: January 21, 2019. \\ Pre-published: January 24, 2019.}

doi:10.3324/haematol.2018.200832

Check the online version for the most updated information on this article, online supplements, and information on authorship \& disclosures: www.haematologica.org/content/104/8/1580

\section{(C)2019 Ferrata Storti Foundation}

Material published in Haematologica is covered by copyright. All rights are reserved to the Ferrata Storti Foundation. Use of published material is allowed under the following terms and conditions:

https://creativecommons.org/licenses/by-nc/4.0/legalcode. Copies of published material are allowed for personal or internal use. Sharing published material for non-commercial purposes is subject to the following conditions:

https://creativecommons.org/licenses/by-nc/4.0/legalcode, sect. 3. Reproducing and sharing published material for commercial purposes is not allowed without permission in writing from the publisher.

\section{ABSTRACT}

A lthough it is well known that myeloproliferative neoplasms occur in younger patients, few large cohorts of such patients have been reported. Thus, our knowledge about circumstances of diagnosis, outcome and treatment is limited, especially for children and young adults. We therefore performed a systematic review of cases, published since 2005, concerning patients aged below 20 years at the time of diagnosis of essential thrombocythemia or polycythemia vera. We identified 396 cases of essential thrombocythemia and 75 of polycythemia vera. The median age at diagnosis was 9.3 and 12 years, respectively, and females constituted $57.6 \%$ and $45 \%$ of the groups, respectively. Half of the patients were asymptomatic at diagnosis. The proportion of so-called triple negativity was high: $57 \%$ in essential thrombocythemia and $73 \%$ in polycythemia vera. The incidence of thrombosis during the follow-up was $9.3 \%$ in patients with polycythemia vera and less, $3.8 \%$, in those with essential thrombocythemia. Venous events were predominant (84.2\%), with hemorrhagic episodes being rarer $(<5 \%)$. The risk of evolution also seemed low ( $2 \%$ to myelofibrosis and no reports of acute leukemia), but the median follow-up was only 50 months. Survival curves were not available. Half of the patients received an antithrombotic drug and $40.5 \%$ received a cytoreductive drug. All data should be analyzed with care because of the proportion of missing data $(10.7 \%$ to $74.7 \%)$. This review highlights interesting points concerning this population of young patients with myeloproliferative neoplasms, including that such patients were identified as negative for all common driver mutations, but also shows the need for larger contemporary cohorts with longer follow-up to assess the true prognosis of these patients.

\section{Introduction}

Essential thrombocythemia (ET) and polycythemia vera (PV) are the most prevalent myeloproliferative neoplasms (MPN). However, the median age at diagnosis of both conditions is over 60 years. Patients with these diseases are particularly exposed to risks of thromboembolic events and evolution into more aggressive disorders (myelofibrosis, myelodysplastic syndromes and acute myeloid leukemia), with a consequent heavy burden of morbidity and mortality.

Current clinical guidelines concerning the diagnosis and management of ET and $\mathrm{PV}$ are generally written for older patients and emphasize that testing for a driver mutation and a bone marrow biopsy are fundamental to diagnose an MPN and that treatment should be adapted according to a classification into low risk or high risk based on the patients' age and history of thrombosis or hemorrhage (prescription of aspirin and cytoreductive drugs) in order to reduce the occurrence of thrombosis. ${ }^{2 \cdot 4}$ 
Details of some large cohorts of young patients with MPN, defined sometimes as below 60 and at other times as below 40 years old, have already been published. ${ }^{5-8}$ Notwithstanding these publications, there are only sparse data concerning very young patients with MPN (aged below 20 years at diagnosis), particularly regarding details such as initial characteristics (reason for consultation, clinical features, bone marrow biopsy features) and outcomes (thrombosis, pregnancy, disease evolution, incidence of second cancer and survival). Furthermore, the utilization of therapeutic modalities in this population is largely unknown. For example, the proportions of very young patients treated with antiplatelet and/or cytoreductive therapies and the therapeutic goals are very poorly defined and, furthermore, there is no information about the potential, long-term sequelae of the treatments.

Here we present a review of published cases of ET and PV patients below the age of 20 years at the time of diagnosis. The earliest data collection point we chose was 2005, coincident with important discoveries concerning the molecular pathogenesis of these conditions, so that we would have more information about the mutational status of the patients and to improve the likelihood of ruling out reactive conditions confounding the diagnosis. ${ }^{9-12} \mathrm{We}$ describe the biological and clinical characteristics at the time of diagnosis and the incidence of vascular and longterm complications during the follow-up.

\section{Methods}

\section{PubMed research}

The purpose of this review was to learn more about young patients diagnosed with MPN: their characteristics at diagnosis and the incidence of complications. To our knowledge there has been no systematic review of the published cases. We used PubMed (https://Www.ncbi.nlm.nih.gov /pubmed) to identify articles related to our topic.

\section{A}

\section{Driver mutations in ET patients}

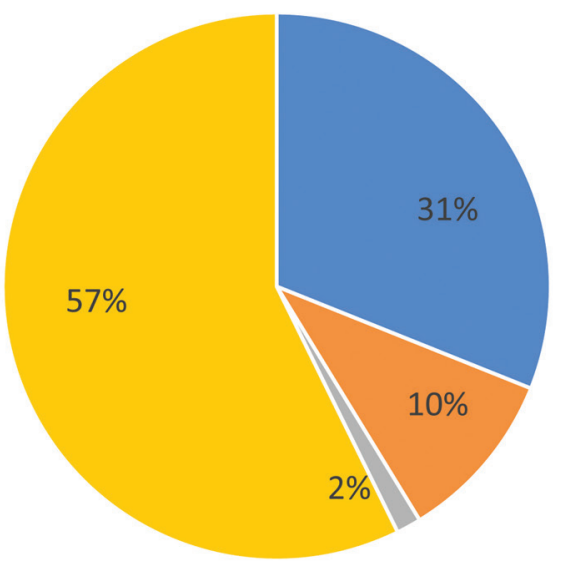

- JAK2V617F $=\mathrm{CALR}=\mathrm{MPL} \backsim 3 \mathrm{NEG}$
For this review, we analyzed papers referring only to patients with ET or PV who were under 20 years old at the time of the diagnosis. The keywords used during the research were: polycythemia vera, primary or essential thrombocythemia/thrombocytosis, myelofibrosis, myeloproliferative neoplasms or diseases, young patients/adults, children/childhood and pediatric cases. To avoid the bias of recording misdiagnosed PV cases, only papers published since 2005 were eligible, coincident with the date of the discovery of the $J A K 2^{\mathrm{V} 617 \mathrm{~F}}$ mutation. Furthermore, we directly excluded familial MPN cases, if this was clearly specified in the title or the text. All types of articles were collected: general reviews, cohort papers (including more than 5 patients) and case reports (including fewer than 5 patients).

\section{Selection of the articles}

We identified 87 articles concerning MPN and young patients and we finally analyzed 46 articles after exclusion of redundant papers (same authors, same numbers of patients), uninformative cases (no information about diagnosis or outcomes), alternative myeloid diseases (primary myelofibrosis, acute leukemia), inadequate age identification (cohorts of young patients, but below 40 years old) as delineated in the PRISMA flowchart (Online Supplementary Figure S1) and the checklist (Online Supplementary Table S1).

In total, we identified 46 informative articles: 19 cohort papers (16 on ET and 3 on PV) and 27 case reports (23 on ET and 11 on $\mathrm{PV}$, with some concerning both conditions). ${ }^{9.56} \mathrm{We}$ also added seven papers with useful information concerning epidemiology. ${ }^{57-63}$

\section{Collected characteristics}

All informative articles were printed (published articles and supplementary data) and searched data were extracted and reported in an Excel file.

The following data collected at the time of diagnosis were recorded: age, sex, circumstances of diagnosis (e.g. thrombosis), symptoms (hyperviscosity, pain, fatigue, pruritus, microvascular events), full blood count (leukocyte, hemoglobin and platelet levels), previous cardiovascular events (thrombosis and hemorrhage), 
molecular status (JAK2 $2^{\mathrm{V} 61 \mathrm{~F}}$ or JAK2 exon 12, positivity for CALR or MPL, JAK2 allele burden) and detailed molecular analysis.

The duration of the follow-up was assessed as precisely as possible, the prescribed drugs and the incidence of complications were then recorded: rate and type of antithrombotic drugs (lowdose aspirin, clopidogrel, vitamin $\mathrm{K}$ antagonists, heparins), rate and type of cytoreductive drugs (hydroxycarbamide, anagrelide, interferon, ruxolitinib, others), together with information on venesection requirement, incidence of cardiovascular events (thromboses and hemorrhages), evolution (ET into PV, ET or PV into secondary myelofibrosis or acute leukemia), and death. With regards to the thrombotic events, the type of vessel and the localization were recorded.

\section{Results}

\section{Epidemiology}

Only a few papers considered epidemiological data specifically for the MPN population and, it was sometimes difficult to assess the presence or absence of chronic myelogenous leukemia among the cases described. Furthermore, there was great variability in the incidence of MPN between countries (United Kingdom, Denmark, Europe, Japan), in the timing of the observation (from 1980 to 2010) and in the age of the patients (below 14 to below 25 years old).

Overall, we found that the global incidence of MPN, in children and young adults, can be estimated to be around 0.82/100,000 patients/year (range, 0.1 to 2.25 ): the incidence of ET is around 0.6/100,000 patients/year (range, 0.004 to 0.9 ), against 0.18 for $\mathrm{PV}$ and 0.53 for primary myelofibrosis (range, 0.003 to 1.5 ).

\section{Clinical and biological data at diagnosis}

\section{Clinical characteristics}

On analyzing the published literature, we were able to collect data on 471 patients, of whom 396 (84\%) had ET and $75(16 \%)$ had PV. These patients' clinical and biological characteristics are summarized in Table 1. For each described parameter, we also give the number and the percentage of data available in the published population. The median age at diagnosis was 9.3 years for ET patients and 12 years for PV patients. The percentage of female cases was also different between the two groups (57.6\% in ET and $45 \%$ in PV).

The reason for the original consultation was unclear or unknown in most cases. At the time of the diagnosis, $49.6 \%$ of the ET patients and $47.5 \%$ of PV were declared to be asymptomatic. For the other patients, the two most frequent symptoms experienced were headaches $(27.5 \%$ in ET and $30.5 \%$ in PV) followed by abdominal or bone pain $(5.5 \%$ and $3.4 \%$, respectively). As a potential bias, a group of 30 patients with ET were declared to suffer from microvascular disturbances but without a more precise description. Interestingly, $13.6 \%$ of PV patients and $4.7 \%$ of ET patients were diagnosed following a thrombotic or hemorrhagic event.

Splenomegaly was the most frequent abnormal sign described in the papers: $54.7 \%$ of ET and $15.3 \%$ of PV patients had a palpable spleen. Surprisingly, its presence did not seem to have induced so many abdominal symptoms as there were discrepancies between frequencies of splenomegaly and reported abdominal pain. It is also hard to understand the much higher frequency of splenomegaly in ET and the fact that this does not seem to have correlated with abdominal vein thrombosis, for example.

Table 1. Clinical and biological characteristics at diagnosis of very young patients with essential thrombocythemia or polycythemia vera.

\begin{tabular}{|c|c|c|}
\hline & Essential thrombocythemia & Polycythemia vera \\
\hline Number of cases (\%) & $396(84)$ & $75(16)$ \\
\hline $\begin{array}{l}\text { Median age (years) } \\
\text { Range (years) }\end{array}$ & $\begin{array}{c}9.3 \\
0.2-20\end{array}$ & $\begin{array}{c}12 \\
0.6-19\end{array}$ \\
\hline Male (\%) & 42.4 & 55 \\
\hline $\begin{array}{l}\text { Reasons for consultation or symptoms, } \mathrm{n}(\%) \\
\text { Asymptomatic } \\
\text { Thrombosis } \\
\text { Hemorrhage } \\
\text { Splenomegaly } \\
\text { Headaches } \\
\text { Abdominal/bone pain } \\
\text { Paresthesia/erythromelalgia } \\
\text { Syncope } \\
\text { Fatigue } \\
\text { Pruritus }\end{array}$ & $\begin{array}{c}* 236(59.6) \\
117(49.6) \\
7(3) \\
4(1.7) \\
129(54.7) \\
65(27.5) \\
13(5.5) \\
11(4.7) \\
3(1.3) \\
2(0.8) \\
0\end{array}$ & $\begin{array}{c}* 59(78.7) \\
28(47.5) \\
5(8.5) \\
3(5.1) \\
9(15.3) \\
18(30.5) \\
2(3.4) \\
1(1.7) \\
3(5.1) \\
4(6.8) \\
3(5.1)\end{array}$ \\
\hline $\begin{array}{l}\text { Full blood counts at presentation } \\
\text { Leukocytes, } x 10^{9} / \mathrm{L} \\
\text { Hemoglobin, } \mathrm{g} / \mathrm{L} \\
\text { Platelets, } \times 10^{9} / \mathrm{L}\end{array}$ & $\begin{array}{c}* 229(57.8) \\
10.6 \\
131 \\
1192\end{array}$ & $\begin{array}{c}* 67(89.3) \\
13.2 \\
157 \\
799\end{array}$ \\
\hline $\begin{array}{l}\text { Driver mutations } \\
J A K 2 \text { exon } 14, \mathrm{n} \\
\text { Allele burden, } \% \\
\text { JAK2 exon } 12, \mathrm{n} \\
\text { CALR, } \mathrm{n} \\
M P L, \mathrm{n}\end{array}$ & $\begin{array}{c}* 388(98.2) \\
130 \\
24.1 \\
- \\
23 \text { (typel, } \mathrm{n}=9 ; \text { type2, } \mathrm{n}=6) \\
4(\mathrm{~L}, \mathrm{n}=2 ; \mathrm{K}, \mathrm{n}=1)\end{array}$ & $\begin{array}{c}* 75(100) \\
30 \\
43.5 \\
2 \\
-\end{array}$ \\
\hline
\end{tabular}

*indicates the number and percent of available data for each category of parameters. 


\section{Biological characteristics}

The results of the full blood count at diagnosis are presented in Table 1. For ET patients, the median leukocyte count was $10.610^{9} / \mathrm{L}$, the hemoglobin concentration was $131 \mathrm{~g} / \mathrm{L}$ and the platelet count was $1192 \times 10^{9} / \mathrm{L}$ (maximum $4500 \times 10^{9} / \mathrm{L}$ ). For PV patients, the median leukocyte count was $13.2 \times 10^{9} / \mathrm{L}$, the hemoglobin concentration was 180 $\mathrm{g} / \mathrm{L}$ (maximum level, $189 \mathrm{~g} / \mathrm{L}$ ), the maximum hematocrit was $72.5 \%$ and the platelet count was $799 \times 10^{\circ} / \mathrm{L}$. It is difficult to understand how hereditary thrombocytosis and erythrocytosis were excluded for these patients.

To assess the diagnosis of MPN, many authors wrote in the "Patients and methods" section that their patients fulfilled the diagnostic criteria according to the 2001, 2008 or 2016 World Health Organization classification. However, bone marrow results were described for less than $52 \%$ of the ET and $44 \%$ of the PV cases. Generally, the descriptions were short with a conclusion expressed as "compatible with MPN".

\section{Molecular analyses}

Considering the entire cohort of PV patients, we noted that only $37 \%$ and $2.5 \%$ were positive for JAK2 exon 14 and exon 12 mutations, respectively. Three studies comprehensively assessed the presence of both types of JAK2 mutations: the percentage of JAK2 exon 14 cases decreased to $24 \%$ whereas, the rate of JAK2 exon 12 mutations remained stable at $3 \%$ (Figure $1 \mathrm{~A}) .,{ }^{9,13,24}$ According to these results, the percentage of patients positive for the V617F mutation in exon 14 is far less than in adults, whereas that of exon 12 is identical. Consequently, the percentage of patients who do not harbor one of these two mutations is also high: $73 \%$. Information on $J A K 2^{\mathrm{V} 617 \mathrm{~F}}$ allele burden was available in a small number of studies and the mean value was $43.5 \%$. This finding of much lower rates of $J A K 2$ mutation in young patients with $\mathrm{PV}$ is also unexpected and requires a prospective evaluation, including, for example, the role of red cell isotopic studies to confirm the diagnosis.

The analysis in ET patients is more complex because of the number of mutations to test. Notwithstanding, in a global analysis, the percentages of positivity were $31.7 \%$ for $J A K 2^{\mathrm{V} 617 \mathrm{~F}}, 5.6 \%$ for $C A L R$ and $1 \%$ for MPL mutations Analyzing the eight cohorts of ET patients in whom all driver mutations were tested, the proportions of positivity became $31 \%$ for $J A K 2^{\mathrm{V} 617 \mathrm{~F}}, 10 \%$ for $C A L R$, and $2 \%$ for $\mathrm{MPL}$ and so $57 \%$ of the cases were triple-negative (Figure 1B). 12,14,16,17,19,20,22,33 These percentages are quite different from those in adults, among whom there is a much higher frequency of triple-negative cases and lower percentages of JAK2- or CALR-positive cases. ${ }^{64}$ As for PV patients, the number of studies reporting $J A K 2^{\mathrm{V} 617 \mathrm{~F}}$ allele burden was small and the mean value was $24.1 \%$. As discussed earlier the exclusion of hereditary cases is critical here.

Interestingly, two groups have reported the results of next-generation sequencing analyses in this population. ${ }^{12,16}$ Among 68 patients tested the authors found that 35\% did not carry any of the tested non-driver mutations. Most of the patients carried only one additional mutation. The description and the proportions of non-driver mutations are shown in Figure 2. In one study, patients with ET seemed to have more mutations than PV patients. ${ }^{16}$ The presence of mutations belonging to the high molecular risk group and inducing worse prognosis in primary myelofibrosis is uncommon in this population (ASXL1 in 4 cases and $I D H 1 / 2$ in 1 case) ${ }^{65,66}$ As far as concerns young patients with ET or PV, the real clinical significance of these nondriver mutations cannot be assessed from the studies.

\section{Outcomes and survival}

\section{Thrombotic events}

As noted above, some very young patients were diagnosed with MPN because of the occurrence of a thrombotic event. The exact incidence of thrombosis at diagnosis was $14.7 \%$ and $4 \%$ in PV and ET patients, respectively. So, these events seemed quite infrequent compared to their frequency in adults. ${ }^{67-68}$ Importantly, the incidence of thrombosis after the diagnosis of MPN decreased in the PV cohort (9.3\%), but remained stable in the ET patients (3.8\%) (Table 2).

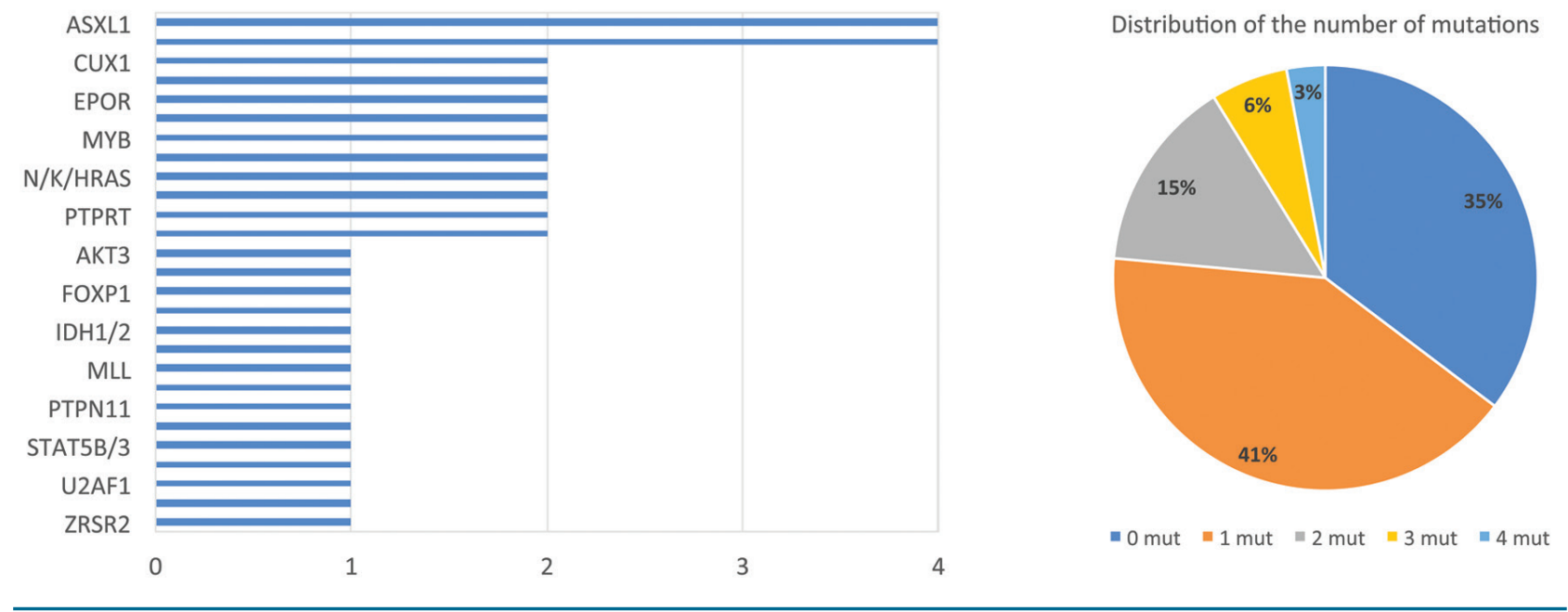

Figure 2. Description and numbers of non-driver mutations identified by next-generation sequencing in two studies (68 patients). ${ }^{12,16}$ mut: mutations. 
Global analyses of recurrence of thrombotic events are not available here since most of the data were published for entire groups and not for individuals. However, considering only the case reports $(n=25)$, we recorded ten patients with ET who experienced a thrombotic event before or at diagnosis and only one had a recurrence during the follow up $(10 \%)$. Among PV cases $(n=10)$, five patients were in the same situation and two of them had a new thrombotic event (40\%). Since this only represents a small group there is a risk of bias in these data.

Interestingly, the overall ratio of arterial/venous events $(\mathrm{r}=0.2)$ demonstrates a clear predominance of venous events $(84.2 \%)$. This situation was identical both before and after the diagnosis. Concerning the sites of the events, thromboses of the splanchnic territories were most frequent $(75 \%$ of the venous events), with a large predominance of Budd-Chiari syndrome $(62.5 \%$ of all venous events). Again, this is very different from the situation in the adult population (Online Supplementary Table S2).

\section{Hemorrhagic events}

The number of hemorrhagic episodes seemed very low (1\% before and $4.8 \%$ after the diagnosis in ET patients and $4 \%$ in both situations in PV patients). Importantly, the use of an antithrombotic drug did not seem to increase the risk of hemorrhage. The episodes described in the literature were mostly minor events, but their localization was usually unknown.

\section{Transformation}

As one of the most significant complications of MPN, transformation into secondary myelofibrosis and/or acute myeloid leukemia is a major concern. Such transformation frequently provokes a deterioration of the Performance Status and the necessity to change treatment strategy (i.e., to use ruxolitinib, allogeneic transplantation or intensive chemotherapy). Reassuringly, transformation seemed unusual in very young patients with MPN, with only $2 \%$ of cases evolving into myelofibrosis and none transforming into acute myeloid leukemia. However, this and other information about complications during the follow-up should be interpreted carefully because of the relatively short median follow-up of the cohorts and the case reports (54 and 51.3 months for ET and PV patients, respectively).

\section{Another malignancy and long-term sequelae of therapy}

Interestingly, Cario and colleagues observed that three among 36 PV patients (8.3\%) were diagnosed with their MPN after having been cured from acute leukemia (2 cases) or lymphoma (1 case). ${ }^{9}$ There are only two cohorts of patients for which the occurrence of solid cancers in the young ET and PV patients was reported, with only one case of kidney cancer observed (1/97 patients, 1\%). There is no information or evidence about the potential implications of previous chemotherapy or cytoreductive drugs on the occurrence of MPN or cancer, despite the possible risk

Table 2. Treatments and outcomes of very young patients with essential thrombocythemia or polycythemia vera.

\begin{tabular}{|c|c|c|}
\hline & Essential thrombocythemia & Polycythemia vera \\
\hline $\begin{array}{l}\text { Antithrombotic drugs, n (\%) } \\
\text { Not treated } \\
\text { Low dose aspirin } \\
\text { Vitamin-K antagonists } \\
\text { Subcutaneous heparin }\end{array}$ & $\begin{array}{c}* 203(51.3) \\
104(51.2) \\
88(43.3) \\
11(5.4) \\
7(3.4)\end{array}$ & $\begin{array}{c}* 59(78.7) \\
37(62.7) \\
19(32) \\
7(11.9) \\
6(10.2)\end{array}$ \\
\hline $\begin{array}{l}\text { Cytoreductive drugs, n (\%) } \\
\text { Not-treated } \\
\text { Hydroxycarbamide } \\
\text { Anagrelide } \\
\text { Interferon } \\
\text { Venesections } \\
\text { Ruxolitinib } \\
\text { Busulfan/Melphalan/22P } \\
\text { Allogeneic SCT } \\
\text { Thrombo/Erythropheresis }\end{array}$ & $\begin{array}{c}* 239(60.3) \\
112(46.9) \\
31(13) \\
50(20.9) \\
11(4.6) \\
0 \\
0 \\
0 \\
0 \\
1(0.4)\end{array}$ & $\begin{array}{c}* 62(82.7) \\
6(9.7) \\
16(25.8) \\
0 \\
6(9.7) \\
28(45.2) \\
1(1.6) \\
7(11.3) \\
3(4.8) \\
4(6.5)\end{array}$ \\
\hline $\begin{array}{l}\text { Complications before diagnosis, } \mathrm{n}(\%) \\
\text { Thrombosis } \\
\text { Hemorrhage }\end{array}$ & $\begin{array}{l}* 307(77) \\
16(4) \\
4(1)\end{array}$ & $\begin{array}{c}* 69(92) \\
11(14.7) \\
3(4)\end{array}$ \\
\hline $\begin{array}{l}\text { Complications after diagnosis, n (\%) } \\
\text { Thrombosis } \\
\text { Hemorrhage }\end{array}$ & $\begin{array}{l}* 307(77) \\
15(3.8) \\
19(4.8)\end{array}$ & $\begin{array}{c}* 69(92) \\
7(9.3) \\
3(4)\end{array}$ \\
\hline $\begin{array}{l}\text { Transformation, n (\%) } \\
\text { Total } \\
\text { Polycythemia vera } \\
\text { Myelofibrosis } \\
\text { Acute leukemia }\end{array}$ & $\begin{array}{c}* 264(68.7) \\
7(1.8) \\
0 \\
7(1.8) \\
0\end{array}$ & $\begin{array}{c}* 19(25.3) \\
2(2.7) \\
- \\
2(2.7) \\
0\end{array}$ \\
\hline Death $(\mathrm{n} / \%)$ & 0 & $3(4)$ \\
\hline Follow-up (months) & 54 & 51.3 \\
\hline
\end{tabular}

*indicates the number and percent of available data for each category of parameters. ${ }^{32} \mathrm{P}$ : radioactive phosphorus; SCT: stem cell transplantation 
of these treatments modifying the genetic environment. Similarly, there are no data about the occurrence of other diseases which might be significant during the MPN, such as autoimmune, cardiac or inflammatory diseases.

Surprisingly, only one study reported data on pregnancy: six young women experienced 15 pregnancies which resulted in nine healthy babies and six miscarriages $(40 \%)$. This latter percentage is much higher than in the latest cohorts of young adult women with MPN, but should be interpreted with caution. ${ }^{69}$

\section{Survival and death}

The mortality rate seemed low (3 cases, $0.65 \%$ ): two patients died after the occurrence of Budd-Chiari syndrome despite adequate management, highlighting the fact that this event has a very high risk of morbidity and mortality, and one patient died of pneumonia that developed following a stroke. It should be noted that information about death was probably subject to reporting bias, and the median follow-up was short.

\section{Treatments}

It is not clear in the published literature whether adult or pediatric staff made decisions on these patients nor what age cut-off, if any, might have been used to decide therapy. Also, it is not clear what strategy for venesection was used for these young patients. In our review, we observed a relatively high frequency of prescription of "antithrombotic" drugs (51.2\% in ET and $62.7 \%$ in PV patients). The description of the treatments is provided in Table 2. The rate of prescription of aspirin was higher in ET patients than in PV patients $(43.3 \%$ vs. $32 \%$ ) whereas, PV patients were more frequently treated with vitamin K antagonists or low molecular weight heparin $(22.1 \%$ vs. $8.8 \%$ in ET patients, respectively). These differences were probably due to the rate of thrombosis observed among PV patients (mostly Budd-Chiari syndrome). It is difficult to know whether these medications could have been responsible for the occurrence of the hemorrhages reported during the follow-up.

As expected in this population, there was a very low number of high-risk patients $(5.7 \%)$ based on a history of thrombosis (data on the number of patients with platelet counts over $1500 \times 10^{9} / \mathrm{L}$ were not available). Despite the low percentage of high-risk patients, most of the subjects were treated with a cytoreductive drug or related therapy $(60.8 \%)$. The description of the treatments is available in Table 2. The reasons for prescribing these treatments were not explained.

Most of the ET patients received what would be regarded as non-leukemogenic drugs, such as anagrelide $(20.9 \%)$ or interferon (4.6\%). Most of the PV patients were treated with phlebotomy ( $45.2 \%$ plus $6.5 \%$ erythropheresis), but a substantial proportion of them also received hydroxycarbamide $(25.8 \%)$. The use of interferon seemed quite uncommon $(9.7 \%)$, even for the pegylated formulation (one-third of the interferon-treated population). Interestingly, ruxolitinib (a $J A K 1$ and JAK2 inhibitor) was prescribed in only one explicit case (three other cases were cited in a phase II trial, but without available data). Surprisingly, $16.1 \%$ of the PV patients were treated with melphalan, busulfan, radioactive phosphorus or allogeneic stem cell transplantation: most of these patients were treated in the 1980s and are represented by one cohort of patients.

\section{Discussion}

We have described here the clinical and biological parameters of very young patients (aged $<20$ years at diagnosis of ET or PV) whose data have been published since 2005. Interestingly in this cohort of over 470 cases the clear majority (84\%) had ET, which remains unexplained. Another interesting fact is that only a few cases were discovered because of the presence of symptoms (mostly headaches or migraines) or due to a thrombotic event. Importantly, the occurrence of thrombosis, hemorrhage or evolution of disease seemed quite rare.

We found that a comprehensive, or total, description of all the published cases is almost impossible. As a possible bias, some cases could also have been published in large series of young patients (under 40 years old) and we were unable to extract data specifically pertinent to our age group of interest. Furthermore, almost all the information was reported in a global way, i.e. not for individual cases and, as shown, a lot of information concerning each specific data point was lacking (the amount of missing data varied from $10.7 \%$ to $74.7 \%$ ), illustrating the difficulties of our approach.

Concerning the diagnosis of MPN, bone marrow biopsy is generally regarded as essential, as illustrated recently by Putti and colleagues who demonstrated, in a descriptive study of biopsies from very young ET patients, that only $16(76 \%)$ of the 21 bone marrow biopsies were compatible with a diagnosis of ET. Furthermore, they also confirmed the usefulness of this examination by identifying one case of PV, three cases of prefibrotic myelofibrosis and even one non-MPN case. ${ }^{19}$ There is no such study on bone marrow biopsies among PV patients. It should be noted that there is no evidence to tell us that the management or the outcome of very young patients with prefibrotic myelofibrosis needs to be different from that of ET patients, so this remains a matter for further evaluation. In fact, it is interesting to speculate that had more biopsies been performed, the large excess of ET diagnoses may have changed.

Surprisingly, a large proportion of this cohort of young patients with MPN was found to be negative for all common driver mutations. For the patients with ET, this proportion was $57 \%$, which is higher than that reported in adult series (between 10\% to 20\%). ${ }^{70,71}$ About three-quarters of the patients with PV were also negative for any JAK2 mutations, with the proportion varying between $63 \%$ and $75 \%$ depending on the cohorts. ${ }^{9,13,24}$ This raises the question of whether these were real cases of MPN. As many of them were old cases, were they misdiagnosed MPN or real MPN but with different mechanisms of proliferation than the JAK2 pathway? This suggests a potential place for next-generation sequencing in the population of patients negative for driver mutations. A new evaluation with recent cases will be useful to confirm or refute this observation.

With regards to complications, we observed a low rate of both thrombosis and transformation $(4.7 \%$ and $1.9 \%$, respectively), which is in accordance with the numbers observed in the young population in general (people aged less than 40 years old) (Table 3 ) but, far less than in old people. . $58,8,7,68,72$ Concerning the thrombotic risk, the classification of this population as a low- or very low-risk category seems appropriate (based on their age and history of thrombosis). ${ }^{2}$ Concerning the risk of transformation, reas- 
Table 3. Comparison of the characteristics of the very young patients in this cohort versus those of other reported series of young patients less than $\mathbf{4 0}$ years old with polycythemia vera or essential thrombocythemia.

\begin{tabular}{|c|c|c|c|c|c|c|c|c|c|}
\hline & \multicolumn{5}{|c|}{ Essential thrombocythaemia } & \multicolumn{4}{|c|}{ Polycythaemia vera } \\
\hline & $\begin{array}{l}\text { Our } \\
\text { cohort }\end{array}$ & $\begin{array}{l}\text { Boddu } \\
2018\end{array}$ & $\begin{array}{c}\text { Palandri } \\
2015\end{array}$ & $\begin{array}{l}\text { Lussana } \\
2014\end{array}$ & $\begin{array}{l}\text { Barbui } \\
2012\end{array}$ & $\begin{array}{l}\text { Our } \\
\text { cohort }\end{array}$ & $\begin{array}{l}\text { Boddu } \\
2018\end{array}$ & $\begin{array}{l}\text { Lussana } \\
2014\end{array}$ & $\begin{array}{l}\text { Passamonti } \\
2003\end{array}$ \\
\hline Number & 396 & 105 & 197 & 375 & 178 & 75 & 43 & 97 & 70 \\
\hline Median age, years & 9.3 & 25 & 34 & 32,3 & 33 & 12 & 28 & 35 & 42 \\
\hline Age range, years & $0.2-20$ & $16-39$ & $16-40$ & $16-41$ & $13-40$ & $0.6-19$ & $16-39$ & $18-40$ & $18-49$ \\
\hline Male & $42 \%$ & $27 \%$ & $32 \%$ & $29 \%$ & $38 \%$ & $55 \%$ & $51 \%$ & $44 \%$ & $70 \%$ \\
\hline White blood count, $10^{9} / \mathrm{L}$ & 10.6 & 8.2 & 8.6 & 8.6 & 8.4 & 13.2 & 9.4 & 10.7 & 12 \\
\hline Haemoglobin, g/L & 131 & 134 & 142 & 142 & 14 & 157 & 149 & 190 & 210 \\
\hline Platelets, $10^{9} / \mathrm{L}$ & 1192 & 763 & 850 & 708 & 796 & 799 & 547 & 476 & 544 \\
\hline$J A K 2^{\text {V6lif }}$ cases & $33.5 \%$ & $53 \%$ & $63 \%$ & $100 \%$ & $56 \%$ & $40 \%$ & $92 \%$ & $100 \%$ & $?$ \\
\hline$J A K 2^{\mathrm{V} 617 \mathrm{~F}}$ allele burden & $24.1 \%$ & 15 & $21 \%$ & $?$ & $?$ & $43.5 \%$ & $21 \%$ & $?$ & $?$ \\
\hline Thrombosis before diagnosis & $4 \%$ & $6 \%$ & $8 \%$ & $9 \%$ & $13 \%$ & $14.7 \%$ & $14 \%$ & $12 \%$ & $24 \%$ \\
\hline Venous events & $86 \%$ & $?$ & $68 \%$ & $55 \%$ & $62 \%$ & $78 \%$ & $?$ & $67 \%$ & $29 \%$ \\
\hline Median follow-up, years & 4.5 & 2.6 & 10.3 & 7.3 & 7.6 & 4.3 & 3.6 & 7.9 & 14 \\
\hline Thrombosis after diagnosis & $3.8 \%$ & $2 \%$ & $10 \%$ & $10 \%$ & $8 \%$ & $9.3 \%$ & $2 \%$ & $18 \%$ & $11 \%$ \\
\hline Hemorrhage after diagnosis & $4.8 \%$ & $2 \%$ & $?$ & $?$ & $5 \%$ & $4 \%$ & $5 \%$ & $?$ & $?$ \\
\hline Transformation into PV & $0 \%$ & $?$ & $0 \%$ & $0 \%$ & $0 \%$ & na & na & na & na \\
\hline Transformation into MF & $1.8 \%$ & $0 \%$ & $5.5 \%$ & $3 \%$ & $3 \%$ & $2.7 \%$ & $0 \%$ & $9 \%$ & $7 \%$ \\
\hline Transformation into AML & $0 \%$ & $2 \%$ & $0.5 \%$ & $0 \%$ & $0 \%$ & $0 \%$ & $0 \%$ & $3 \%$ & $7 \%$ \\
\hline Death & $0 \%$ & $8 \%$ & $2.7 \%$ & $0.5 \%$ & $0 \%$ & $4 \%$ & $0 \%$ & $4 \%$ & $26 \%$ \\
\hline
\end{tabular}

PV: polycythemia vera; MF: myelofibrosis; AML: acute myeloid leukemia.

suringly, there were no cases of post-ET PV or acute myeloid leukemia, and the death rate was very low. However, we note a possible bias since most of the papers described particular data (e.g., thrombosis, bone marrow examinations, molecular analysis) as the main message, not reporting the parameters at diagnosis or detailed follow-up information; furthermore, we should also be cautious because of the short median follow-up of the patients included in this review (around 50 months). These factors could have led us to underestimate the rates of long-term complications. Thus, while the overall survival seems long, there are no published survival curves and the median follow-up, as discussed already, is quite short for this population of subjects who would normally be expected to live a further 60-70 years, if their life expectancy is similar to that of the general population.

We noted a clear prevalence of venous thrombosis with a complete inversion of the ratio of arterial/venous thrombotic events (0.2), compared to that in cohorts of adults in whom this ratio is close to 0.67 (Online Supplementary Table S1). ${ }^{1}$ Interestingly, we observed a predominance of portal vein thrombosis and Budd-Chiari syndrome, mostly at diagnosis, a situation similar to that in the adult population in whom these thromboses are frequently associated with MPN and induce significant morbidity and mortality (2 of the 3 deaths reported in this review). ${ }^{9}$ On the other hand, $83 \%$ of the arterial events occurred during the follow-up and all these events were localized in the cerebral area. Given the age of the patients and the very low supposed rate of cardiovascular risk factors (not evaluated here as unavailable), and the different mutation profiles it will be interesting to understand the mechanism of these thromboses.

Since the ECLAP study, the prescription of low-dose aspirin is highly recommended in older patients, especially with $\mathrm{PV}$, to reduce the risk of thrombosis. ${ }^{73}$ The benefit of using this drug has not been proven for either ET patients or for very young patients. Furthermore, Alvarrez-Larran and colleagues have published a retrospective study on the use of antiplatelet drugs among young (defined as less than 60 years old) patients with ET, and found that CALRpositive patients experienced more hemorrhages when treated with aspirin. ${ }^{74}$ Effectively, given their metabolism, children are exposed to a higher risk of aspirin-related gastrointestinal and intracranial hemorrhages. Children below 12 years old seem particularly at risk of Reye syndrome because of the interaction between aspirin and coenzyme A reductase in mitochondria. ${ }^{75,76}$ In Reye syndrome, gastrointestinal symptoms (nausea and vomiting) are followed by progressive encephalopathy (i.e. somnolence) until coma and death due to multi-organ failure. Unfortunately, stopping the administration of aspirin does not automatically reverse the process. The incidence of Reye syndrome among very young patients with ET and $\mathrm{PV}$ is unknown and there have been no published cases in the past 12 years.

According to international guidelines, in the adult ET and PV population, the prescription of a cytoreductive drug is limited to patients who are classified as being at high risk of thrombosis based on age (recommended if $>60$ years or younger with a cardiovascular risk factor) or platelet count $>1500 \times 10^{9} / \mathrm{L}$ or a history of thrombosis. ${ }^{2}$ For patients belonging to the low-risk group, no other drug than aspirin is recommended. Thus, in this very young population with low rates of prior thrombosis, aspirin should often have been the only therapy. However, the proportion of patients receiving cytoreductive drugs was unexpectedly high in this population (60.8\%), and the reasons were not explained.

Given ongoing concerns about the safety of hydroxycarbamide it seems surprising perhaps that this drug was so frequently prescribed in this population of young patients. On the other hand, the relative innocuity of hydroxycarbamide has been proven in many cohorts of patients with 
sickle cell disease. ${ }^{77}$ In contrast, the use of interferons was quite uncommon even though these drugs are non-leukemogenic and the first line of cytoreductive drugs according to the European LeukemiaNet recommendations. It is important to remember that all these medications, even hydroxycarbamide, are currently unlicensed in this population. Also, there are few data concerning the side effects and the long-term consequences of the use of these drugs.

The European LeukemiaNet recommendations do not appear to have been followed closely in the population we analyzed, but at the same time, there are no adapted recommendations for the treatment of MPN in very young patients. This is potentially a substantial shortcoming since young people are not small adults and also because there is no real large cohort of patients in whom to assess the risks, outcomes and medications in a prospective manner. Thus, we propose a large pan-European study concerning very young patients. The aims of this study should be multiple: to gain a more accurate overview of the clinical and biological parameters concerning this population at diagnosis (symptoms and the way of making the diagnosis) and to obtain a clearer understanding of the incidence of thromboses, hemorrhages and disease progression. Such a study should also federate clinicians and biologists interested in the field in order to manage these patients better with the help of pediatricians.

\section{References}

1. Tefferi A, Barbui T. Polycythemia vera and essential thrombocythemia: 2017 update on diagnosis, risk-stratification, and management. Am J Hematol. 2017;92(1): 94-108.

2. Barbui T, Barosi G, Birgegard G, et al; European LeukemiaNet. Philadelphia-negative classical myeloproliferative neoplasms: critical concepts and management recommendations from European LeukemiaNet. J Clin Oncol. 2011;29(6):761-770.

3. Arber DA, Orazi A, Hasserjian R, et al. The 2016 revision to the World Health Organization classification of myeloid neoplasms and acute leukemia. Blood. 2016;127(20):2391-2405.

4. Tefferi A, Guglielmelli P, Larson DR, et al. Long-term survival and blast transformation in molecularly annotated essential thrombocythemia, polycythemia vera, and myelofibrosis. Blood. 2014;124(16):2507-2513.

5. Boddu P, Masarova L, Verstovsek S, et al. Patient characteristics and outcomes in adolescents and young adults with classical Philadelphia chromosome-negative myeloproliferative neoplasms. Ann Hematol. 2018;97(1):109-121.

6. Palandri F, Latagliata $\mathrm{R}$, Polverelli $\mathrm{N}$, et al. Mutations and long-term outcome of 217 young patients with essential thrombocythemia or early primary myelofibrosis. Leukemia. 2015:29(6):1344-1349.

7. Barbui T, Thiele J, Carobbio A, et al. Disease characteristics and clinical outcome in young adults with essential thrombocythemia versus early/prefibrotic primary myelofibrosis. Blood. 2012;120(3):569-571.

8. Passamonti F, Malabarba L, Orlandi E, et al Polycythemia vera in young patients: a study on the long-term risk of thrombosis, myelofibrosis and leukemia. Haematologica. 2003;88(1):13-18.

9. Cario H, McMullin MF, Pahl HL. Clinical and hematological presentation of children and adolescents with polycythemia vera. Ann Hematol. 2009;88(8):713-719.

10. Costa G, Petit A, Ianotto JC, et al Thrombocytémie essentielle (TE) chez l'enfant et le jeune adulte. Rev Oncol Hemato Ped. 2016:4(4):253-254.

11. El-Moneim AA, Kratz CP, Böll S, Rister M, Pahl HL, Niemeyer CM. Essential versus reactive thrombocythemia in children: retrospective analyses of 12 cases. Pediatr Blood Cancer. 2007;49(1):52-55.

12. Fu R, Liu D, Cao Z, et al. Distinct molecular abnormalities underlie unique clinical features of essential thrombocythemia in children. Leukemia. 2016;30(3):746-749.

13. Giona F, Teofili L, Moleti ML, et al. Thrombocythemia and polycythemia in patients younger than 20 years at diagnosis: clinical and biologic features, treatment, and long-term outcome. Blood. 2012;119(10): 2219-2227.

14. Giona F, Teofili L, Capodimonti S, et al. CALR mutations in patients with essential thrombocythemia diagnosed in childhood and adolescence. Blood. 2014:123(23):36773679.

15. Ismael $O$, Shimada $A$, Hama $A$, et al Mutations profile of polycythemia vera and essential thrombocythemia among Japanese children. Pediatr Blood Cancer. 2012;59(3): 530-535.

16. Karow A, Nienhold R, Lundberg P, et al. Mutational profile of childhood myeloproliferative neoplasms. Leukemia. 2015;29(12): 2407-2409.

17. Langabeer SE, Haslam K, McMahon C. CALR mutations are rare in childhood essential thrombocythemia. Pediatr Blood Cancer. 2014;61(8):1523.

18. Nakatani $T$, Imamura $T$, Ishida $H$, et al. Frequency and clinical features of the JAK2 V617F mutation in pediatric patients with sporadic essential thrombocythemia. Pediatr Blood Cancer. 2008;51(6):802-805.

19. Putti MC, Pizzi M, Bertozzi I, et al. Bone marrow histology for the diagnosis of essential thrombocythemia in children: a multicenter Italian study. Blood. 2017;129(22): 3040-3042.

20. Randi ML, Geranio G, Bertozzi I, et al. Are all cases of paediatric essential thrombocythemia really myeloproliferative neoplasms? Analysis of a large cohort. Br J Haematol. 2015;169(4):584-589.

21. Randi ML, Putti MC, Scapin M, et al. Pediatric patients with essential thrombocythemia are mostly polyclonal and V617FJAK2 negative. Blood. 2006;108(10): 3600-3602

22. Sekiya Y, Okuno Y, Muramatsu $\mathrm{H}$, et al. JAK2, MPL, and CALR mutations in children with essential thrombocythemia. Int J Hematol. 2016;104(2):266-267.

23. Teofili L, Cenci T, Martini M, et al. The mutant JAK2 allele burden in children with essential thrombocythemia. Br J Haematol. 2009:145(3):430-432

24. Teofili L, Giona F, Martini M, et al. The revised WHO diagnostic criteria for $\mathrm{Ph}$-neg- ative myeloproliferative diseases are not appropriate for the diagnostic screening of childhood polycythemia vera and essential thrombocythemia. Blood. 2007;110(9):33843386.

25. Veselovska J, Pospisilova D, Pekova S, et al. Most pediatric patients with essential thrombocythemia show hypersensitivity to erythropoietin in vitro, with rare JAK2 V617F-positive erythroid colonies. Leuk Res. 2008;32(3):369-377.

26. Aladily TN, Mohammad RS, Al-Khader A, Awidi AS. Essential thrombocythemia in a two-year-old child, responsive to hydroxyurea but not aspirin. Oman Med J. 2017;32(3):243-246

27. Beatrice JM, Garanito MP. Essential thrombocythemia: a rare disease in childhood. Rev Bras Hematol Hemoter. 2013;35(4):287-289.

28. Dua V, Yadav SP, Kumar V, Saxena R, Sachdeva A. Two cases of pediatric essential thrombocythemia managed effectively with hydroxyurea. Int J Hematol. 2012;96(6):810813.

29. Hermeziu B, Franchi-Abella S, Plessier A, et al. Budd-Chiari syndrome and essential thrombocythemia in a child: favorable outcome after transjugular intrahepatic portosystemic shunt. J Pediatr Gastroenterol Nutr. 2008:46(3):334-337.

30. Hwang J, Lee W. A case of essential thrombocythemia in an 8-year-old boy. Pediatr Hematol Oncol. 2008:25(4):325-330.

31. Jaime-Perez JC, Gomez-Almaguer D. Platelet refractoriness to classical agonists in a child with essential thrombocythemia. Platelets. 2005;16(1):61-62.

32. Jensen AW, Tefferi A, Arndt CA. Cerebral venous sinus thrombosis associated with essential thrombocytosis in a pediatric patient. J Pediatr Hematol Oncol. 2007;29(3):156-159.

33. Kanai A, Morokawa H, Matsuda K, Shimazaki E, Nakazawa Y. Efficacy and safety of anagrelide in childhood essential thrombocythemia. Pediatr Int. 2017;59(9): 1017-1018.

34. Khan AA, Kumar V, Anand I, Kumar M, Sharma P, Bhargava M. JAK2 mutation-negative essential thrombocythemia in a child presenting with cerebral venous thrombosis. Hematol Oncol Stem Cell Ther. 2012;5(1): 66-68.

35. Kurosawa H, Okuya M, Matsushita T, et al. JAK2V617F mutation-positive childhood essential thrombocythemia associated with cerebral venous sinus thrombosis. J Pediatr 
Hematol Oncol. 2009;31(9):678-680.

36. Lackner $\mathrm{H}$, Urban C, Benesch M, et al. Longterm use of anagrelide in the treatment of children with essential thrombocythemia. Eur J Haematol. 2006;77(4):358-359.

37. Langabeer SE, Haslam K, McMahon C. A prenatal origin of childhood essential thrombocythemia. Br J Haematol. 2013;163(5): 676-678.

38. Bertrand A, Heissat S, Caron N, et al. Deep vein thrombosis revealing myeloproliferative neoplasm in two adolescents. Arch Ped. 2014;21(5):497-500.

39. Pulini S, D'Amico E, Basilico R, et al. Portal venous thrombosis in a young patient with idiopathic myelofibrosis and intrahepatic extramedullary hematopoiesis: a difficult diagnosis, prognosis and management. Leukemia. 2007;21(11):2373-2375.

40. Robins EB, Niazi M. Essential thrombocythemia in a child with elevated thrombopoietin concentrations and skeletal anomalies. Pediatr Blood Cancer. 2008;50(4):859861.

41. Roy NB, Treacy M, Kench P. Childhood essential thrombocythemia. Br J Haematol. 2005;129(5):567.

42. Scherer S, Ferrari R, Rister M. Treatment of essential thrombocythemia in childhood. Pediatr Hematol Oncol. 2003;20(5):361-365.

43. Singh A, Nityanand S, Sonker A, Kumar S. Successful use of the cell separator Hemonetics multicomponent collection system+ for therapeutic thrombocytapheresis in a low body weight child of essential thrombocythemia. Asian J Transfus Sci. 2015;9(2):207-209.

44. Slone JS, Smith MC, Seegmiller AC, Sidonio RF, Yang E. Idiopathic myelofibrosis in children: primary myelofibrosis, essential thrombocythemia, or transient process? J Pediatr Hematol Oncol. 2013;35(7):559-565.

45. Szegedi I, Benko I, Mero G, Prinzinger A, Kappelmayer J, Kiss C. Long-lasting partial remission by interferon-alpha treatment in a child with essential thrombocythemia. Pediatr Blood Cancer. 2007;49(5):744-747

46. Tokgoz H, Caliskan U, Yüksekkaya HA, Kucukkaya R. Essential thrombocythemia with Mpl W515K mutation in a child presenting with Budd-Chiari syndrome. Platelets. 2015;26(8):805-808.

47. Vafaie M, Jaseb K, Ghanavat M, Pedram M, Rahiminia T. Asymtomatic [sic] essential thrombocythemia in a child: a rare case report. Int J Hematol Oncol Stem Cell Res. 2013;7(2):35-37.

48. Wigton JC, Tersak JM. JAK2+ Essential Thrombocythemia in a young girl with Budd-Chiari syndrome: diagnostic and therapeutic considerations when adult disease strikes the young. J Pediatr Hematol Oncol.
2016:38(1):70-73

49. Benedik-Dolni ar M, Homan M, Brecelj J. JAK2V617F mutation in a 9-year-old girl with polycythemia vera and Budd-Chiar syndrome: a case report. J Pediatr Hematol Oncol. 2012;34(3):243-244.

50. Berman JN, Greer WL, Archambeault S, et al. JAK2 V617F positive polycythemia vera in a child with neurofibromatosis type I. Pediatr Blood Cancer. 2008;51(5):689-691.

51. Braconnier O, Monpoux F, Affanetti M Bérard E, Sirvent N. [Polycythemia vera and JAK-2 mutation in childhood: a case report]. Arch Pediatr. 2007;14(10):1202-1205.

52. Coskun ME, Height S, Dhawan A, Hadzic N. Ruxolitinib treatment in an infant with JAK2+ polycythemia vera-associated BuddChiari syndrome. BMJ Case Rep. 2017;2017.

53. Goldstein G, Maor I, Kleinbaum Y, Palumbo M, Sidi Y, Salomon O. Budd-Chiari syndrome in very young adult patients with polycythemia vera: report of case series with good outcome with direct thrombin inhibitor treatment. Blood Coagul Fibrinolysis. 2013;24(8):848-853

54. Guo HX, Chan GC, Chiang AK, Ho MH, Chan EY, Ha SY. Dural sinus thrombosis owing to polycythemia vera in a 12 -year-old girl. Paediatr Int Child Health. 2012;32 (3):167-170

56. Park MI, Shimada A, Asada H, Koike K, Tsuchida M, Hayashi Y. JAK2 mutation in a boy with polycythemia vera, but not in other pediatric hematologic disorders. Leukemia. 2006;20(8):1453-1454

57. Osgood EE. Polycythemia vera: age relationships and survival. Blood. 1965;26:243-256.

58. Reid MM, Saunders PW, Kernahan J. Myeloproliferative disease in children: a demographic study. J Clin Pathol. 1988;41 (8):883-885

59. McNally RJ, Rowland D, Roman E, Cartwright RA. Age and sex distributions of hematological malignancies in the U.K. Hematol Oncol. 1997;15(4):173-189.

60. Hasle $\mathrm{H}$. Incidence of essential thrombocythemia in children. Br J Haematol. 2000 110(3):751.

61. Visser O, Trama A, Maynadié $M$, et al RARECARE Working Group. Incidence, survival and prevalence of myeloid malignancies in Europe. Eur J Cancer. 2012;48(17): 3257-3266.

62. Horibe K, Saito AM, Takimoto T, et al. Incidence and survival rates of hematological malignancies in Japanese children and adolescents (2006-2010): based on registry data from the Japanese Society of Pediatric Hematology. Int J Hematol. 2013;98(1):74-88.

63. Titmarsh GJ, Duncombe AS, McMullin MF et al. How common are myeloproliferative neoplasms? A systematic review and meta- analysis. Am J Hematol. 2014:89(6):581-587.

64. Rumi E, Cazzola M. Diagnosis, risk stratification, and response evaluation in classical myeloproliferative neoplasms. Blood. 2017;129(6):680-692.

65. Vannucchi AM, Lasho TL, Guglielmelli P, et al. Mutations and prognosis in primary myelofibrosis. Leukemia. 2013;27(9):18611869

66. Tefferi A, Lasho TL, Guglielmelli P, et al. Targeted deep sequencing in polycythemia vera and essential thrombocythemia. Blood Adv. 2016;1(1):21-30

67. Tefferi A, Vannucchi AM, Barbui T. Polycythemia vera treatment algorithm 2018. Blood Cancer J. 2018;8(1):3.

68. Tefferi A, Vannucchi AM, Barbui T. Essential thrombocythemia treatment algorithm 2018. Blood Cancer I. 2018:8(1):2.

69. Alimam S, Bewley S, Chappell LC, et al. Pregnancy outcomes in myeloproliferative neoplasms: UK prospective cohort study. Br J Haematol. 2016;175(1):31-36.

70. Klampfl T, Gisslinger H, Harutyunyan AS, et al. Somatic mutations of calreticulin in myeloproliferative neoplasms. N Engl J Med. 2013;369(25):2379-2390.

71. Nangalia J, Massie CE, Baxter EJ, et al Somatic CALR mutations in myeloproliferative neoplasms with nonmutated JAK2. N Engl J Med. 2013;369(25):2391-2405.

72. Lussana F, Carobbio A, Randi ML, et al. A lower intensity of treatment may underlie the increased risk of thrombosis in young patients with masked polycythemia vera. $\mathrm{Br}$ J Haematol. 2014;167(4):541-546.

73. Landolfi R, Marchioli R, Kutti J, et al, European Collaboration on Low-Dose Aspirin in Polycythemia Vera Investigators. Efficacy and safety of low-dose aspirin in polycythemia vera. N Engl J Med. 2004;350 (2):114-124.

74. Alvarez-Larrán A, Pereira A, Guglielmelli P, et al. Antiplatelet therapy versus observation in low-risk essential thrombocythemia with a CALR mutation. Haematologica. 2016;101 (8):926-931

75. Belay ED, Bresee JS, Holman RC, Khan AS Shahriari A, Schonberger LB. Reye's syndrome in the United States from 1981 through 1997. N Engl J Med. 1999;340 (18):1377-1382.

76. Bennett MJ, Russell LK, Tokunaga C, et al Reye-like syndrome resulting from novel missense mutations in mitochondrial medium- and short-chain 1-3-hydroxy-acyl-CoA dehydrogenase. Mol Genet Metab. 2006:89(1-2):74-79.

77. McGann PT, Ware RE. Hydroxyurea for sickle cell anemia: what have we learned and what questions still remain? Curr Opin Hematol. 2011;18(3):158-165. 